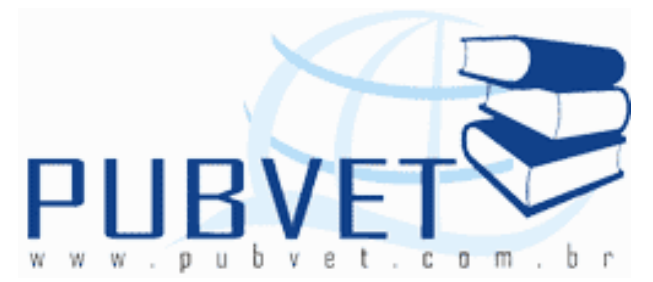

PUBVET, Publicações em Medicina Veterinária e Zootecnia.

\title{
Glicerina bruta de biodiesel na alimentação de ruminantes
}

Ana Carolina Dalmaso ${ }^{1 *}$, Verônica Bandeira Ferreira ${ }^{1}$, Claudio Jonasson

Mousquer ${ }^{1}$, Wanderson José Rodrigues de Castro ${ }^{1}$, Amorésio Souza Silva

Filho $^{1}$, Tiago Adriano Simioni ${ }^{2}$, Alvair Hoffmann ${ }^{2}$, Geferson Antonio Fernandes ${ }^{3}$

${ }^{1}$ Mestrandos em Ciência Animal, PPGCA, UFMT, Cuiabá-MT, Brasil

${ }^{2}$ Mestrandos em Zootecnia, PPZ, UFMT, SINOP-MT, Brasil

${ }^{3}$ Zootecnista, UFMT, Sinop-MT, Brasil

*E-mail: anacarolinadalmaso@zootecnista.com.br

\section{Resumo}

O biodiesel é considerado um combustível ecológico, biodegradável não tóxico e praticamente livre de enxofre e compostos aromáticos. Quando em substituição ao diesel convencional, o biodiesel pode reduzir a emissão de hidrocarbonetos e monóxido de carbono, com a busca de fontes renováveis. Para cada tonelada de biodiesel, são produzidos cerca de $100 \mathrm{~kg}$ de glicerol, com o acúmulo desse coproduto no meio ambiente pode causar a contaminação do solo e da água, com isso, pesquisas estão sendo desenvolvidas para buscar alternativas para a utilização do excedente de glicerol. O custo com a alimentação animal gira em torno de $70 \%$ de toda a produção. E uma das formas de estar diminuindo esse custo com a alimentação é o aproveitamento dos subprodutos como a glicerina na 
DALMASO, A.C. et al. Glicerina bruta de biodiesel na alimentação de ruminantes. PUBVET, Londrina, V. 8, N. 12, Ed. 261, Art. 1733, Junho, 2014.

alimentação animal e ainda ajudando a preservar os recursos naturais (não contaminação ambiental).

Palavras-chave: Animal, Nutrição, Zootecnia.

\title{
Crude glycerin biodiesel in ruminant feed
}

\begin{abstract}
Biodiesel is considered an environmentally friendly fuel, biodegradable, nontoxic, and virtually free of sulfur and aromatics, when replacing the conventional diesel, biodiesel can reduce emissions of hydrocarbons and carbon monoxide with the search for renewable sources. For each ton of biodiesel are produced about $100 \mathrm{~kg}$ of glycerol, with the accumulation of this coproduct in the environment can cause contamination of soil and water, thus, research is being undertaken to find alternatives to the use of surplus glycerol. The cost of animal feed is around $70 \%$ of all production. And one of the ways to be decreasing this cost power is the use of by-products like glycerin in animal feed and also helping to preserve natural resources (no pollution).Biodiesel is considered an environmentally friendly fuel, biodegradable, nontoxic, and virtually free of sulfur and aromatics, when replacing the conventional diesel, biodiesel can reduce emissions of hydrocarbons and carbon monoxide with the search for renewable sources. For each ton of biodiesel are produced about $100 \mathrm{~kg}$ of glycerol, with the accumulation of this coproduct in the environment can cause contamination of soil and water, thus, research is being undertaken to find alternatives to the use of surplus glycerol. The cost of animal feed is around $70 \%$ of all production. And one of the ways to be decreasing this cost power is the use of by-products like glycerin in animal feed and also helping to preserve natural resources (no pollution).
\end{abstract}

Keywords: Animal, Nutrition, Animal Science. 
DALMASO, A.C. et al. Glicerina bruta de biodiesel na alimentação de ruminantes. PUBVET, Londrina, V. 8, N. 12, Ed. 261, Art. 1733, Junho, 2014.

\section{INTRODUÇÃO}

Diversos países procuram o caminho do domínio tecnológico em busca de fontes renováveis, como o biodiesel, que é considerado um combustível ecológico e se destaca por ser biodegradável, não tóxico, e, praticamente livre de enxofre e compostos aromáticos, podendo assim reduzir a emissão de monóxido de carbono e de hidrocarbonetos quando em substituição ao diesel convencional.

O Brasil se destaca por apresentar uma grande produção de grãos que são usados para a extração de óleo vegetal. Com esse grande potencial de produção, o Governo Federal intensificou as discussões sobre a produção e o uso do biodiesel. Após muitos estudos, foi criado o Programa Brasileiro de Desenvolvimento Tecnológico do Biodiesel (PROBIODIESEL). Esse programa visa à substituição parcial do diesel pelo biodiesel. Dentro de quinze anos, está prevista a entrada do B20 (20\% de biodiesel e $80 \%$ de diesel) (Pousa et al., 2007). Para que isso ocorra, o Ministério de Minas e Energia lançou o programa Combustível verde - Biodiesel, e foi estabelecida a meta para a produção de 1,5 milhão de toneladas de biodiesel. Com esse incentivo, houve um crescimento enorme na produção de biodiesel, porém há um fator preocupante com esse crescimento, que é destino do glicerol excedente. Segundo (Bowker et al., 2008) para cada tonelada de biodiesel são produzidos cerca de $100 \mathrm{~kg}$ de glicerol. Com isso, pesquisas estão sendo desenvolvidas para buscar alternativas para a utilização do excedente de glicerol.

Uma das alternativas para utilização desse coproduto seria a inclusão na alimentação de ruminantes (Oliveira, 2008). Visto também que o custo com a alimentação animal representa $70 \%$ do custo de produção, o aproveitamento desses subprodutos torna-se uma alternativa para diminuir os custos com a alimentação. De acordo com Brás (2011), o acúmulo desse coproduto no meio ambiente, consequentemente gera contaminação ambiental (solo e água), a inclusão na alimentação de ruminantes colabora também com a preservação dos recursos naturais e com a produção animal sustentável. 
DALMASO, A.C. et al. Glicerina bruta de biodiesel na alimentação de ruminantes. PUBVET, Londrina, V. 8, N. 12, Ed. 261, Art. 1733, Junho, 2014.

\subsection{Biodiesel}

O biodiesel é definido como um mono-alquil éster de ácidos graxos, obtido pela transesterificação de óleos vegetais com alcoóis, metanol ou etanol, por meio da catálise básica com hidróxido de sódio $(\mathrm{NaOH})$ ou hidróxido de potássio $(\mathrm{KOH})$ ou ainda pela esterificação desses materiais na presença de catalisadores ácidos, com consequente transformação dos triglicerídeos em moléculas menores de ésteres de ácidos graxos, tendo como coproduto a glicerina bruta (Thompson \& He, 2006).

\subsection{Histórico do biodiesel}

Em 1893 o engenheiro alemão Rodolf C.K. Diesel desenvolveu o primeiro motor a diesel do mundo, abastecido com óleo vegetal feito a partir de amendoim.

No Brasil, a partir do ano 1920 o Instituto Nacional de Tecnologia - INT estudava e testava combustíveis alternativos e renováveis a partir da palma, algodão e amendoim.

Em 1970 a Universidade Federal do Ceará (UFC) desenvolveu estudos sobre fontes alternativas de energia que culminaram com a revelação de um novo combustível: o Biodiesel.

No ano de 1980 ocorreu o primeiro registro da patente mundial do biodiesel obtida pelo Prof. Expedito Parente da UFC - Patente "PI-8007959". No começo dos anos 90 é iniciado na Europa o processo de industrialização do biodiesel. Na ocasião, o principal mercado produtor e consumidor desse biocombustível em grande escala já era a Europa.

No dia 06 de dezembro de 2004 foi lançado o Programa Brasileiro de Produção e Uso do Biodiesel - PNPB. Foram se sucedendo edições de leis, atos normativos e regulamentos que formam todo o arcabouço legal que norteia as iniciativas do biodiesel no Brasil.

Em janeiro de 2005 foi publicada a Lei no 11.097 que dispõe sobre a introdução do biodiesel na matriz energética brasileira. A partir dessa 
DALMASO, A.C. et al. Glicerina bruta de biodiesel na alimentação de ruminantes. PUBVET, Londrina, V. 8, N. 12, Ed. 261, Art. 1733, Junho, 2014.

publicação a ANP assumiu a atribuição de regular e fiscalizar as atividades relativas ao biodiesel. Realização do 10 leilão. Adição facultativa de $2 \%$ do biodiesel no diesel.

Em meados de 2008 e 2009 ocorreu o início obrigatório da mistura de $2 \%$ de biodiesel no diesel. Em junho de 2008 é autorizado o aumento para 3\% do biodiesel no diesel (Resolução n02 do conselho Nacional de Política Energética - CNPE), e em julho de 2009 entrou em vigor a adição de 4\% de biodiesel.

A partir do dia primeiro de janeiro de 2010 entrou em vigor a Resolução CNPE, n० 6/2009, que permite a adição de 5\% de biodiesel no diesel. (Ubrabio, 2008, com atualização EMBRAPA).

\subsection{Importância e uso do Biodiesel}

Segundo a ANP (2010), no Brasil, o biodiesel teve sua comercialização impulsionada pelo aumento no teor da adição de 3 para $4 \%$ de biodiesel, no diesel de petróleo, ocorrido em julho de 2009. Com isso, as vendas de biodiesel obtiveram um aumento de $39 \%$ em relação a 2008 , embora o crescimento fosse sobre uma base ainda pequena. Todavia, a disseminação do consumo do biodiesel e do etanol, produto da cana-de-açúcar, corroborou em reforçar a posição pioneira do Brasil na utilização de fontes de energia renováveis, frente aos demais países mundiais.

Atualmente, os Estados Unidos é o maior produtor de biodiesel do mundo, com uma produção estimada na capacidade instalada de 5.912 milhões de litros em 2010, seguida pela Alemanha com 5.047 milhões de litros (GBC, 2011). Contudo a ANP (2010), destaca que o Brasil esta entre os maiores produtores e consumidores de biodiesel, existindo aproximadamente 69 plantas de biodiesel autorizadas para operação no País, com capacidade total de 17.415,95 m³/dia. A produção anual, em 2010, foi de 2.400 milhões de litros, 50\% mais que em 2009 e com capacidade instalada para produzir 4.700 milhões de litros (BIODIESELBR, 2011). 
A produção no Estado de Mato Grosso no ano de 2010 foi de 640,1 mil $\mathrm{m}^{3}$ de biodiesel, respondendo por $39 \%$ de toda a produção nacional, tornando o Estado o principal produtor.

De acordo com Lofrano (2008), muitas matérias-primas podem ser utilizadas na produção de biodiesel e podem ser divididas nos seguintes grupos: óleos vegetais, gordura animal e gorduras residuais. 0 biodiesel brasileiro é baseado em mais de $70 \%$ em óleo de soja, os $30 \%$ restantes são feitos a partir do sebo e gorduras animais e outras fontes (Figura 1).

\section{Matérias-primas utilizadas na produção de biodiesel}

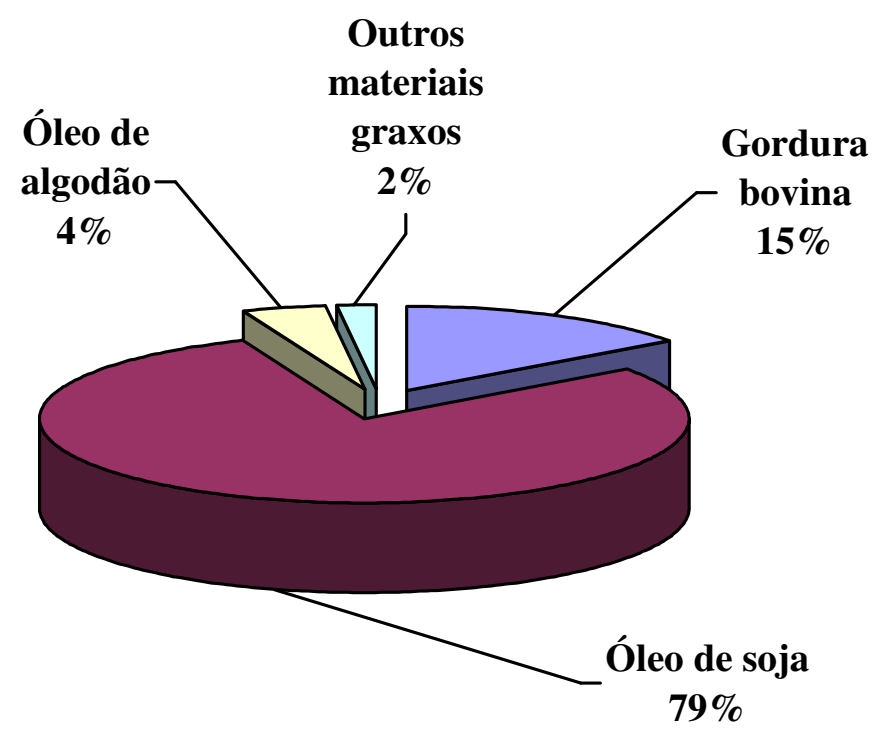

Figura 1 - Matérias-primas utilizadas na produção de biodiesel. (ANP, 2010).

Óleo vegetal usado na produção de biodiesel é um triglicerídeo (Figura 2), ou seja, um triéster derivado da glicerina. Sobre a ação de um catalisador básico e na presença de metanol ou etanol, o óleo sofre uma transesterificação formando três moléculas de ésteres metílicos ou etílicos dos ácidos graxos, que constituem o biodiesel em sua essência, e liberando uma molécula de glicerol ou glicerina (Mota, 2009). 
DALMASO, A.C. et al. Glicerina bruta de biodiesel na alimentação de ruminantes. PUBVET, Londrina, V. 8, N. 12, Ed. 261, Art. 1733, Junho, 2014.

A principal rota de obtenção do biodiesel é a partir da transesterificação de óleos vegetais com alcoóis (metanol e etanol), usando catálise básica.

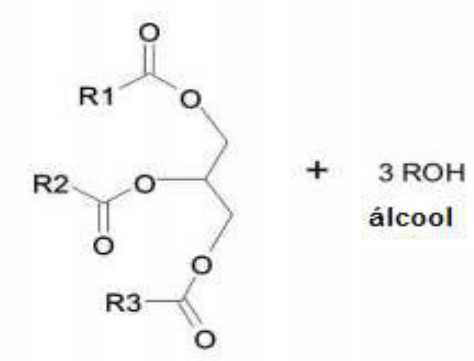

Triglicerídeos (óleo vegetal- gordura animal)

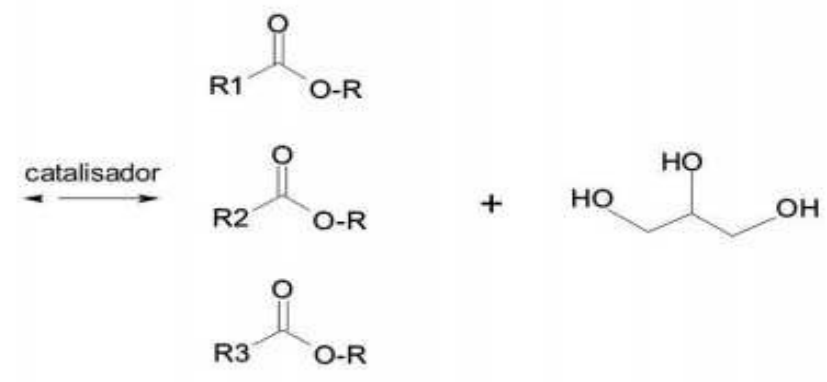

ésteres (biodiesel)

glicerol

Figura 2 - Reação global de transesterificação dos triglicerídeos (Rivaldi, et al., 2007)

O processo de produção do biodiesel segue as seguintes etapas (Figura 3): 1) preparação da matéria-prima, 2) reação de transesterificação, 3) separação de fases, 4) recuperação, 5) desidratação do álcool e 6) purificação da glicerina e do biodiesel. 
DALMASO, A.C. et al. Glicerina bruta de biodiesel na alimentação de ruminantes. PUBVET, Londrina, V. 8, N. 12, Ed. 261, Art. 1733, Junho, 2014.

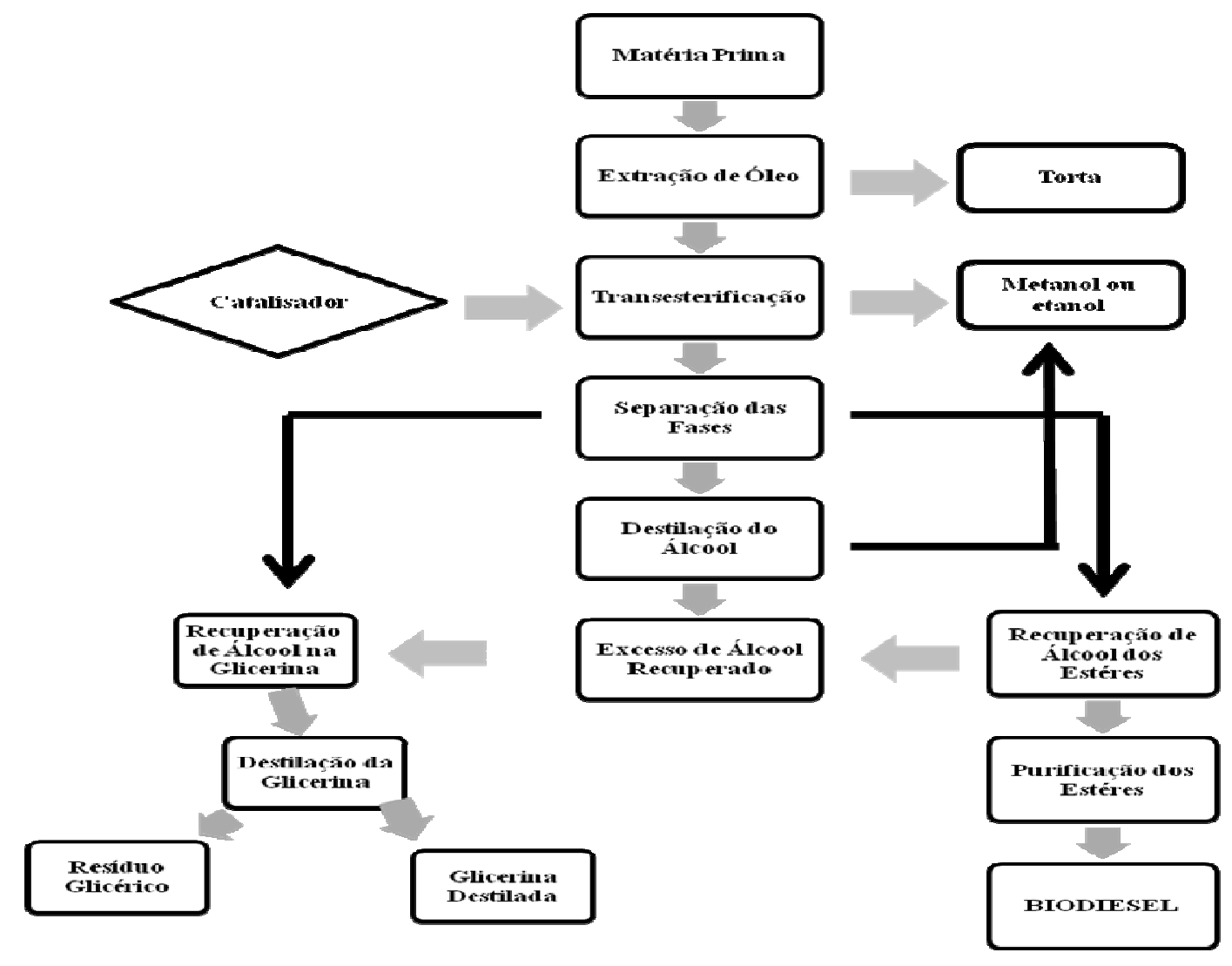

Figura 3 - Fluxograma da produção do biodiesel (Adaptado de Marchetti et al., 2007).

\subsection{Glicerina}

O glicerol (Figura 4) foi primeiramente descoberto em 1.779 por Scheele, pelo aquecimento de uma mistura de óxido de chumbo com azeite de oliva. $\mathrm{Na}$ época, ele o batizou de "o doce princípio das gorduras". O termo glicerol aplica-se somente ao componente químico puro 1,2,3-propanotriol.<smiles>OCC(O)CO</smiles>

Figura 4 - Glicerol (Knothe et al., 2006) 
O termo glicerina bruta aplica-se aos produtos comerciais purificados, normalmente, contendo pelo menos 95\% de glicerol. Em geral, esta glicerina (Tabela 1) contém cerca de $80 \%$ de glicerol, além de água, metanol e sais dissolvidos.

Tabela 1 - Composição da glicerina variando na pureza

\begin{tabular}{cccc}
\hline & \multicolumn{3}{c}{ Pureza da Glicerina } \\
\hline Umidade (\%) & Baixa & Média & Alta \\
\hline Glicerol & 26,8 & 1,1 & 2,5 \\
\hline Extrato Etéreo & 63,3 & 85,3 & 99,8 \\
\hline P & 0,71 & 0,44 & n.a. \\
\hline K & 1,05 & 2,36 & n.a. \\
\hline Na & 2,20 & 2,33 & n.a. \\
\hline Pb & 0,11 & 0,09 & n.a. \\
\hline Metanol & 0,0003 & 0,0002 & n.a. \\
\hline
\end{tabular}

Fonte: Zacaroni, 2010

De acordo com Pinto et al. (2005) a inclusão de $2 \%$ de biodiesel no diesel, gerou uma produção de 80 mil toneladas de glicerina bruta por ano e uma demanda nacional de 14.080 toneladas por ano, gerando excedentes. Para cada $90 \mathrm{~m}^{3}$ de biodiesel produzido por transesterificação são gerados, aproximadamente, $10 \mathrm{~m}^{3}$ de glicerina (Mota, 2009).

A glicerina, quando purificada, tem várias aplicações industriais, entre as quais se destacam os usos em tabaco (Figura 5), alimentos, bebidas e cosméticos (Peres et al., 2005). No entanto, são necessários processos complexos e de alto custo para que essa matéria-prima alcance as exigências em grau de pureza necessárias para estes fins (Diniz, 2005), visto que a 
DALMASO, A.C. et al. Glicerina bruta de biodiesel na alimentação de ruminantes. PUBVET, Londrina, V. 8, N. 12, Ed. 261, Art. 1733, Junho, 2014.

glicerina bruta apresenta impurezas como água, catalisador (alcalino ou ácido), impurezas provindas dos reagentes, ácidos graxos, ésteres, etanol ou metanol, propanodióis, monoéteres e oligômeros de glicerina.

Principais indústrias de utilização da glicerina

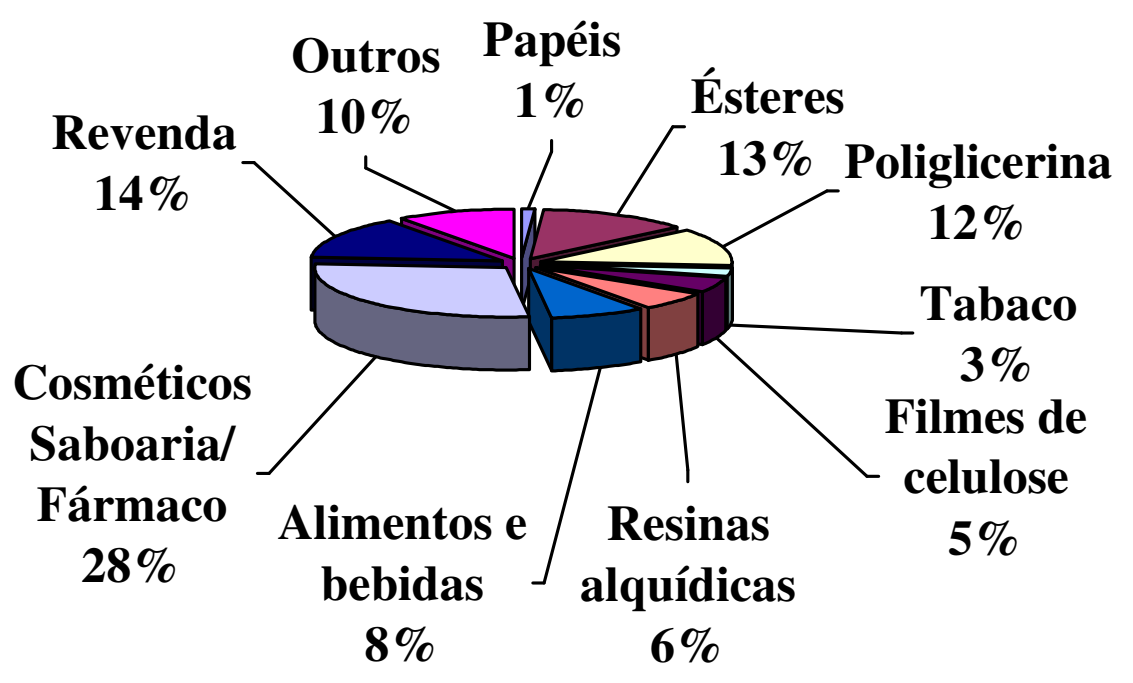

Figura 5 - Principais indústrias de utilização da glicerina, Peres (2005).

Grandes usinas de biodiesel refinam sua própria glicerina para melhorar o preço do produto no mercado, mas esta solução não é viável para as usinas de médio porte, as quais não possuem volume suficiente para justificar a montagem de uma refinaria, disponibilizando então o excedente de glicerina bruta no varejo. Nesse sentido, os baixos preços de mercado da glicerina bruta despertou interesse para uso na alimentação animal, especialmente na bovinocultura, como fonte energética em potencial.

\subsection{Classificação e Composição da Glicerina}

A glicerina é um composto orgânico, líquido a temperatura ambiente $\left(25^{\circ} \mathrm{C}\right)$, higroscópico, inodoro, viscoso e de sabor adocicado. Seu ponto de fusão é de $17,8^{\circ} \mathrm{C}$ e ebulição com decomposição em $290^{\circ} \mathrm{C}$ (ANP, 2010). É classificada em vários graus, tanto pela quantidade de glicerol como pelas 
DALMASO, A.C. et al. Glicerina bruta de biodiesel na alimentação de ruminantes. PUBVET, Londrina, V. 8, N. 12, Ed. 261, Art. 1733, Junho, 2014.

impurezas presentes, como água, lipídios, cinzas e metanol. Embora o glicerol seja incolor, as formas menos puras podem ter sua cor variando do âmbar para um castanho muito escuro (Carvalho, 2011).

A glicerina com alta pureza pode ser utilizada numa infinidade de aplicações industriais, especialmente, em setores alimentícios e farmacêuticos, como agente umectante e de texturização.

As características físicas e químicas da glicerina permitem seu uso em diversas áreas, pelas suas propriedades umectante, plastificante, emoliente, espessante, solvente, dispersante, lubrificante, adoçante e anticongelante (Natural Resources Canadá, 2005). Segundo Carvalho (2011), as características da glicerina bruta dependem do tipo de ácido graxo (gordura animal ou óleo vegetal) e do tipo de catálise empregada na produção de biodiesel.

Oliveira et al. (2010) realizou uma compilação de dados sobre a composição química da glicerina bruta "loira" obtida após a transesterificação do óleo de soja utilizada na alimentação animal (Tabela 2)

Tabela 2 - Estatística descritiva da composição química (base da matéria natural) da glicerina bruta oriunda de óleo de soja utilizada na dieta de animais

\begin{tabular}{ccccc}
\hline Item & Média & Mínimo & Máximo & $\mathbf{n}^{\mathbf{1}}$ \\
\hline Glicerol (\%) & 84,49 & 80,00 & 90,70 & 7,0 \\
Água (\%) & 7,50 & 5,00 & 10,40 & 5,0 \\
\hline Metanol (mg/kg) & 13.000 & 120 & 86.400 & 6,0 \\
\hline Extrato Etéreo (\%) & 1,26 & 0,00 & 6,90 & 6,0 \\
\hline Mineral (\%) & 7,19 & 5,50 & 10,00 & 6,0 \\
\hline Na (\%) & 2,26 & 1,30 & 3,50 & 6,0 \\
\hline
\end{tabular}

Adaptado de Oliveira et al. (2010). 
DALMASO, A.C. et al. Glicerina bruta de biodiesel na alimentação de ruminantes. PUBVET, Londrina, V. 8, N. 12, Ed. 261, Art. 1733, Junho, 2014.

$\mathrm{Na}$ indústria do biodiesel podem ser obtidos quatro tipos de glicerina:

- Glicerina Bruta (Tabela 3): é obtida após a separação do biodiesel. Possui cerca de 40 a 70\% de glicerol (baixo nível), e elevados níveis de catalisadores, álcool, água, ácidos graxos e sabões. O pH é considerado elevado acima de 12;

- Glicerina bruta "loira": é a glicerina bruta após sofrer tratamento ácido, seguido de remoção dos ácidos graxos e sabões. É o principal tipo de glicerina obtida atualmente nas indústrias de biodiesel. Possui cerca de 75 a $90 \%$ de glicerol, o restante é formado por água, sais e metanol. 0 valor de $\mathrm{pH}$ está entre 5 e 6 ;

- Glicerina grau farmacêutico: é a glicerina bruta "loira" após sofrer bidestilação a vácuo e tratamento com absorventes. Contém mais de 99\% de glicerol. Tem grande aplicação nos setores de cosméticos, higiene pessoal, medicamentos e fumo;

- Glicerina grau alimentício: completamente isenta de metanol.

Tabela 3 - Padrão mínimo de qualidade da glicerina bruta para alimentação animal exigido no Brasil

\begin{tabular}{ccc}
\hline Composto & Limite & Valor (base MN*) \\
\hline Glicerol & Valor mínimo & $800 \mathrm{~g} / \mathrm{kg}$ \\
Umidade & Valor Máximo & $130 \mathrm{~g} / \mathrm{kg}$ \\
Metanol & Valor Máximo & $150 \mathrm{mg} / \mathrm{kg}$ \\
Sódio & Valor Máximo garantido pelo fabricante e pode \\
& variar em função do processo produtivo \\
Matéria Mineral & Valor Máximo garantido pelo fabricante e pode \\
& variar em função do processo produtivo \\
\hline
\end{tabular}

Adapatado de Oliveira et al. (2010) Base MN: base na matéria natural. 
DALMASO, A.C. et al. Glicerina bruta de biodiesel na alimentação de ruminantes. PUBVET, Londrina, V. 8, N. 12, Ed. 261, Art. 1733, Junho, 2014.

\subsection{Absorção e Metabolismo do Glicerol}

A glicerina é considerada um alimento energético, (4.320 kcal de energia bruta por kg para o glicerol puro) e com alta eficiência de utilização pelos animais. O glicerol pode ter efeitos positivos sobre a retenção de aminoácidos ou nitrogênio (Cerrate et al., 2006), a ação do glicerol inibindo a atividade das enzimas fosfoenolpiruvato carboxiquinase e glutamato desidrogenase pode resultar em economia dos aminoácidos gliconeogênicos e favorecer a deposição de proteína corporal.

Em mamíferos, o glicerol consumido por meio da dieta tem sua maior absorção nas células da mucosa do intestino delgado (Lin, 1977), sendo metabolizado, principalmente no fígado, onde três quartos (3/4) do glicerol armazenado no organismo são metabolizados pelo fígado (Figura 6) e nos rins, que são responsáveis por utilizarem cerca de um quinto do glicerol armazenado.

Existem três enzimas de grande importância no metabolismo do glicerol, a glicerol quinase; glicerol-3-fosfato oxirredutase; glicerol-3-fosfato desidrogenase (Figura 7), que são moduladas principalmente pela insulina, corticosteroides e hormônios da tireoide, respectivamente. A enzima glicerol quinase, encontrada em grande parte no fígado e rins, pode realizar a oxidação do glicerol para obtenção de energia ou convertê-lo em glicose (Robergs \& Griffin, 1998).

Ao ser ingerido são vários os destinos metabólicos do glicerol, o destino irá depender do tecido alvo e do estado nutricional do animal, sendo destinado imediato para o ciclo de Krebs ou para o fornecimento de esqueleto carbônico para a gliconeogênese, para a transferência de equivalentes redutores do citosol para a mitocôndria - com a geração de 22 ATP, ou como precursor da síntese de triglicerídeos na síntese de novo de ácidos graxos ou como constituinte da molécula do triacilglicerol. 
DALMASO, A.C. et al. Glicerina bruta de biodiesel na alimentação de ruminantes. PUBVET, Londrina, V. 8, N. 12, Ed. 261, Art. 1733, Junho, 2014.

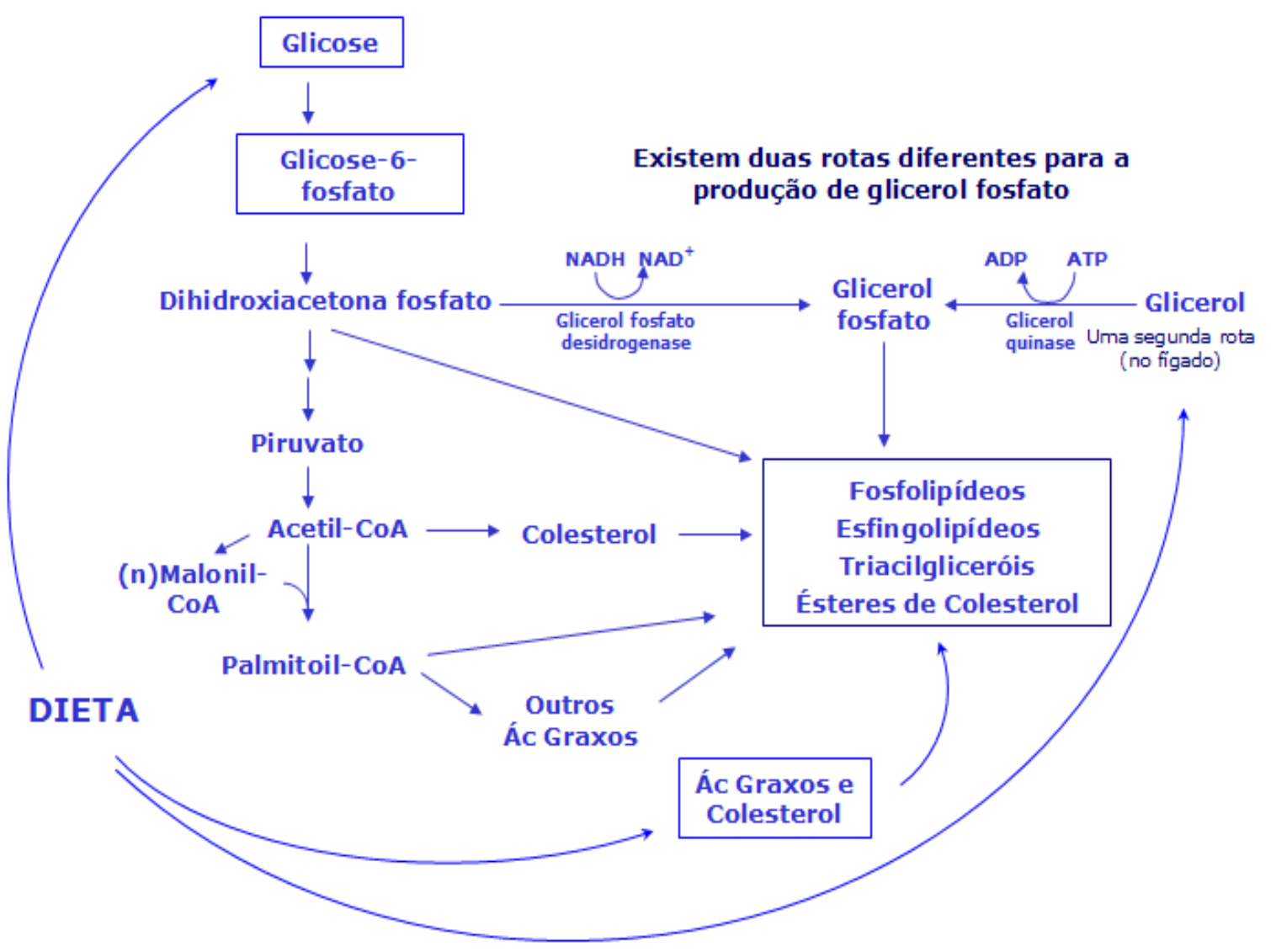

Figura 6 - Metabolismo hepático do glicerol (Lehninger et al., 2000) 
DALMASO, A.C. et al. Glicerina bruta de biodiesel na alimentação de ruminantes. PUBVET, Londrina, V. 8, N. 12, Ed. 261, Art. 1733, Junho, 2014.

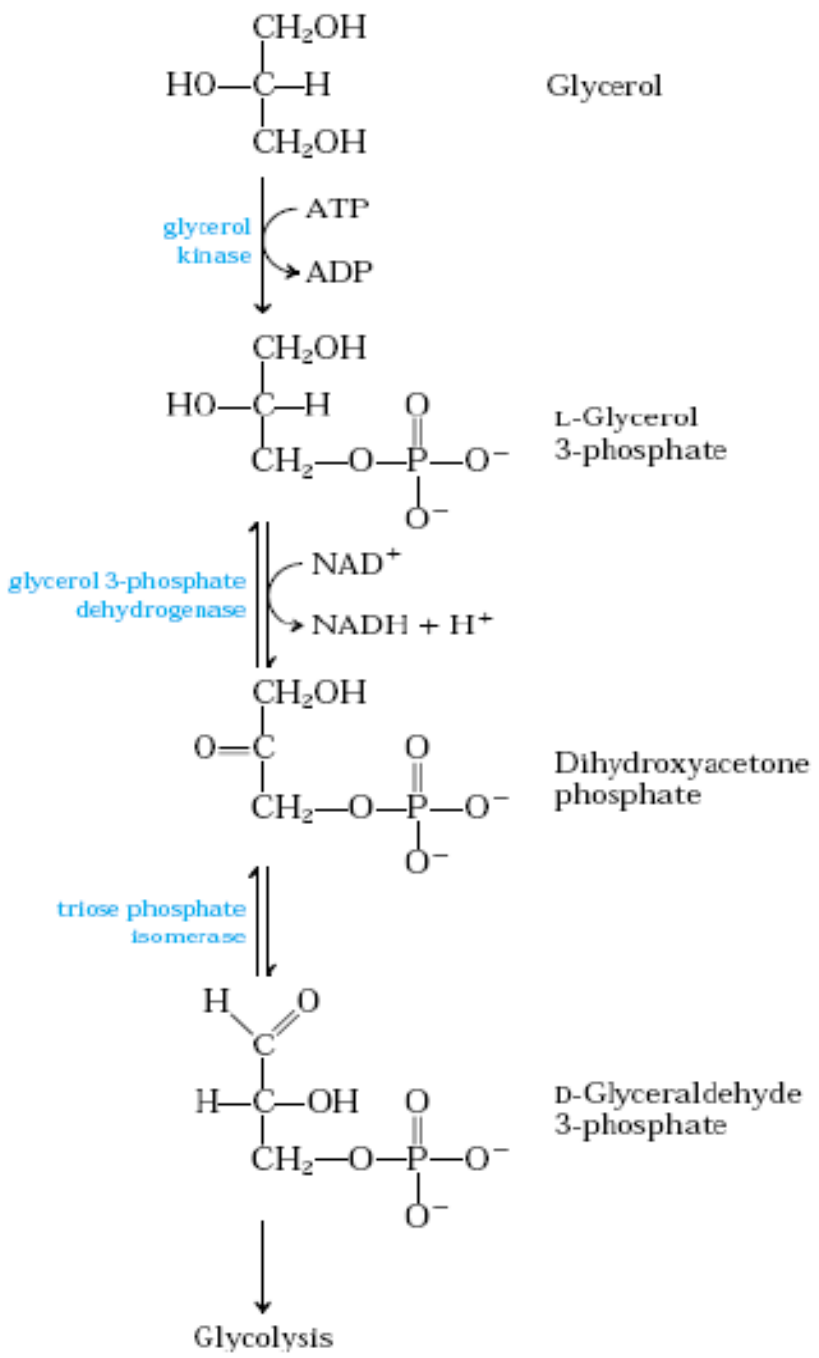

Figura 7 - Conversão do glicerol a intermediários da glicólise (Menten, 2009).

Segundo Donkin, o glicerol não e um carboidrato, porém é fermentado no rúmen a ácidos graxos de cadeia curta, de modo que 50 a $70 \%$ do glicerol desaparecem do rúmen em quatro horas, levando a um aumento na produção de propionato. Outros pesquisadores reportaram aumentos nos teores de acido acético e propiônico ou nos ácidos propiônicos e butíricos (Czerkawski \& Breckenridge, 1972). Remond et al. (1993) também verificaram aumento nos teores de ácido propriônico e butírico avaliando a fermentação in vitro. 
DALMASO, A.C. et al. Glicerina bruta de biodiesel na alimentação de ruminantes. PUBVET, Londrina, V. 8, N. 12, Ed. 261, Art. 1733, Junho, 2014.

\subsection{Uso da Glicerina}

A substituição parcial de lactose por glicerol puro em sucedâneo de leite para bezerros foi avaliada por Drackely et al. (2008) utilizando vinte e quatro bezerros Holandeses, machos e fêmeas, que receberam 1,5\% do peso vivo de sucedâneo de leite com $40 \%$ de lactose ou sucedâneo com $15 \%$ de glicerol na primeira semana de vida e $2 \%$ do peso vivo da segunda a sexta semana.

Os sucedâneos continham teor similar de proteína, gordura, minerais e vitaminas e foram hidratados para obtenção de $15 \%$ de sólidos no produto final. O período experimental foi de 56 dias e os tratamentos foram fornecidos três vezes ao dia, do dia 3 de vida até o dia 49. No dia 43 a quantidade de sucedâneo foi reduzida pela metade e oferecida uma vez ao dia. A partir do dia 36 os bezerros começaram a receber concentrado e o desmame ocorreu com 49 dias. O peso dos bezerros no dia 35 foi $66,9 \mathrm{~kg}$ no Controle e $64,9 \mathrm{~kg}$ no sucedâneo com glicerol $(P=0,28)$. Não foi detectada diferença entre tratamentos na estatura e na incidência de diarreia e pneumonia. Os autores concluíram que a substituição de $37,5 \%$ da lactose no sucedâneo de leite por glicerol foi adequada.

Chung et al. (2007) usando trinta e nove vacas Holandesas, blocadas em pares com base na data do parto e produção de leite na lactação anterior, receberam zero ou $250 \mathrm{~g} / \mathrm{d}$ de glicerina bruta (65\% de glicerol) alocada sobre a dieta completa. A suplementação com glicerina tendeu a aumentar a produção diária de leite na sexta semana da lactação de 46 para $52 \mathrm{~kg}$ $(P=0,14)$. Não foi detectado efeito de tratamento sobre o consumo, metabólitos sanguíneos e a produção e composição do leite durante as três primeiras semanas da lactação.

Schröder \& Südekum, (1999) avaliaram a inclusão de glicerina sobre a digestibilidade da dieta oferecida a ovinos e vacas leiteiras. Os autores avaliaram dois teores de amido na dieta de ovinos e teores de glicerina bruta de 10,15 ou $20 \%$ da MS da dieta. Quando a glicerina foi adicionada à dieta com baixo amido ( $40 \%$ de amido de trigo na MS) não houve efeito sobre as digestibilidades da matéria orgânica, do amido e da FDN, enquanto a inclusão 
DALMASO, A.C. et al. Glicerina bruta de biodiesel na alimentação de ruminantes. PUBVET, Londrina, V. 8, N. 12, Ed. 261, Art. 1733, Junho, 2014.

de glicerina induziu queda na digestibilidade da FDN na dieta com alto amido ( $55 \%$ de amido de trigo na MS).

Esses autores também avaliaram o efeito da substituição de amido de trigo por glicerina na dieta de garrotes, usando quatro garrotes canulados no rúmen recebendo dietas com $40 \%$ de forragem e com $60 \%$ de concentrado peletizado contendo ou não $15 \%$ de glicerina. Não foi detectado efeito da glicerina sobre a digestibilidade, mas ocorreu queda na relação entre acetato e propionato no rúmen $(P<0,05)$ e aumento na concentração de butirato $(P<0,05)$ até três horas após a alimentação. Houve aumento induzido pela glicerina na ingestão de água, maior nos tratamentos com glicerina de baixa e média pureza.

Tabela 4 - Composição da glicerina bruta na matéria natural (MN)

\begin{tabular}{cc}
\hline & \% da MN \\
\hline Ulicerol & 76,2 \\
Umidade & 6,29 \\
Proteína Bruta & 0,29 \\
Extrato Etéreo & 1,33 \\
Cinzas & 2,93 \\
Fósforo & 0,61 \\
Sódio & 0,81 \\
Metanol & $0,88 \mathrm{mg} \mathrm{KOH} / \mathrm{g} \mathrm{de} \mathrm{MN}$ \\
Índice de Acidez & $1,74 \mathrm{Kcal} / \mathrm{d}$ de $\mathrm{MN}$ \\
Energia Bruta & 4,008 \\
\hline
\end{tabular}

Fonte: Zacaroni, 2010.

Linke et al. (2004) citado por Zacaroni (2010), Quando 1,2 kg de glicerol foi infundido em dose única no rúmen de vacas não lactantes, o fluxo de glicerol intacto para o abomaso foi de 7 a $18 \%$ do infundido, enquanto cerca 
DALMASO, A.C. et al. Glicerina bruta de biodiesel na alimentação de ruminantes. PUBVET, Londrina, V. 8, N. 12, Ed. 261, Art. 1733, Junho, 2014.

de metade do infundido desapareceu por metabolismo microbiano no rúmen, sugerindo que ocorreu absorção direta pelo epitélio ruminal.

Remond et al. (1993) citado por Zacaroni, (2010) destacam que o glicerol absorvido pelo epitélio do rúmen precisa passar pelas proteínas integrais de membrana (MIP). Estas são componentes normais da membrana celular, responsáveis pelo equilíbrio osmótico. As MIP são encontradas em bactérias, fungos, insetos, plantas e mamíferos (Froger et al., 2001) e podem ser classificadas em dois subgrupos funcionais: aquaporinas e aquagliceroporinas. As aquaporinas são altamente específicas para conduzir água, por isso são chamadas de canais de água. As aquagliceroporinas são especializadas no transporte de glicerol.

Krehbiel, (2008) relata que cerca de $13 \%$ do glicerol que chega ao rúmen desaparece por passagem com a digesta, $44 \%$ por fermentação e $43 \%$ por absorção pela parede.

Em razão do potencial glicogênico do glicerol, a maioria dos estudos científicos publicados nas últimas décadas sobre 0 uso da glicerina (bidestilada) limitou sua aplicação no tratamento de desordens metabólicas em vacas de leite de alta produção, utilizando-se baixos níveis na dieta (abaixo de 5\%, base da MS) (Johnson et al., 1954; Fisher et al., 1971; 1973; DeFrain et al., 2004). O uso como macroingredientes, no entanto, é recente.

Compilação de resultados de quatro experimentos sobre uso da glicerina bruta do biodiesel (GB) em dietas para bovinos terminados em confinamento de corte, destacam que, os níveis de glicerol variaram de 82 a $86 \%$ e metanol de $0,09 \%$ a 1,25\%. O nível máximo de inclusão de GB variou entre 12 a 30\% na MS da dieta. Todas as glicerinas foram obtidas a partir do óleo de soja. Em apenas um experimento foi observado efeito da GG sobre o desempenho dos animais, com valores máximos de consumo de matéria seca, ganho de peso corporal e eficiência alimentar obtidos com a inclusão de 2\% de GB na dieta (Pearson et al., 2009). Todavia, neste experimento, o desempenho dos animais alimentados com até $12 \%$ de GB na dieta foi semelhante aos animais que não receberam glicerina. O rendimento de carcaça não foi afetado pela 
DALMASO, A.C. et al. Glicerina bruta de biodiesel na alimentação de ruminantes. PUBVET, Londrina, V. 8, N. 12, Ed. 261, Art. 1733, Junho, 2014.

inclusão de GB em três experimentos. O aumento esperado na deposição de gordura intramuscular e do rendimento de carne (área do músculo longissimus dorsi - LD) não foi confirmado nestes experimentos.

Mach et al. (2009) verificaram que a adição de até $12,1 \%$ de GB na dieta de bovinos da raça holandesa não afetou área do músculo Longissimus dorsi (LD) e o seu conteúdo de gordura.

Elam et al. (2008) também verificaram que adição de até 15\% de GB na dieta de novilhas cruzadas (racas continentais vs britânicas) não afetou os indicadores de deposição de gordura intramuscular e de rendimento de carne.

Pearson et al. (2009) por sua vez, observaram redução linear na área do músculo LD e no grau de deposição de gordura intramuscular com o aumento do nível de GB de 2 para 16\% na dieta (base da MS) de novilhas cruzadas (não definido pelos autores). A deposição de gordura subcutânea não foi afetada pela adição de GB.

Assim, até o momento não se confirma os benefícios da alta capacidade glicogênica do glicerol sobre as características de carcaça de bovinos de corte alimentados com GB. Desta forma, justifica-se o uso da GB em substituição à fontes de concentrados energéticos (milho, milheto, farelo de arroz) apenas por conveniência econômica. Potenciais efeitos sobre a redução de emissão de metano ruminal ainda necessitam de confirmação por meio de estudos in vivo de longa duração.

A espermatogênese pode ser comprometida pelo fornecimento de glicerol na dieta. É reconhecido que a administração intratesticular de glicerol causa perturbações no citoesqueleto das células de sertoli e reduz a síntese de lactato nas mesmas, ocasionando déficit energético nas espermátides (Igdoura \& Wiebe, 1994; Wiebe, 2000). Além disso, Gomes (2009) verificou que a adição de 15 e $30 \%$ de GB (83,1\% de glicerol, $0,012 \%$ de metanol e $1,3 \%$ de sódio) na dieta de ovinos ocasionou redução de 77 e $74 \%$ a concentração de espermatozoides no ejaculado de ovinos em confinamento. 
DALMASO, A.C. et al. Glicerina bruta de biodiesel na alimentação de ruminantes. PUBVET, Londrina, V. 8, N. 12, Ed. 261, Art. 1733, Junho, 2014.

\subsection{Limitações do uso da Glicerina}

O processo mais comum de produção de biodiesel o metanol é usado em excesso na reação de transesterificação. Após a formação dos ésteres, há a separação da fase lipídica, com os componentes apolares, e da fase aquosa, com os componentes polares. A glicerina, água e metanol compõem a fase aquosa. A maior parte do metanol é reciclada é recuperado por destilação, retornando ao processo, porém de forma incompleta. A indústria estabelece o valor máximo de 0,5\% metanol na glicerina bruta produzida.

Além de alguns sais, o resíduo de metanol na glicerina bruta se constitui em um ponto importante quando se avalia o valor desse produto para a alimentação animal. O potencial efeito prejudicial do metanol incorporado às rações pode ser desprezado quando a ração for peletizada, uma vez que a temperatura atingida na peletização é mais alta que a temperatura de vaporização do metanol.

Uma avaliação recente da toxicidade do metanol contido na glicerina bruta indicou que as quantidades consumidas, levando em conta a concentração na glicerina e a inclusão desta nas rações, parecem não afetar os animais, a glicerina tem seu uso seguro e reconhecido na alimentação animal, no entanto, o teor de metanol presente na glicerina devera ser levado em consideração, não devendo ultrapassar $150 \mathrm{mg} / \mathrm{kg}$ (Code of Federal Regulations).

\subsection{Perspectivas do Uso da Glicerina}

A glicerina bruta do biodiesel oriunda do óleo de soja, com teor de glicerol acima de $80 \%$, pode ser utilizada em até $10 \%$ na matéria seca de dietas para bovinos de corte em terminação, sem afetar o desempenho reprodutivo, as características da carcaça e a qualidade da carne. Recomendase maior direcionamento para experimentos sobre o uso da glicerina em suplementos para bovinos em pastejo.

Os ruminantes provavelmente toleram níveis de metanol acima do valor máximo exigido atualmente pelos órgãos federais, de $150 \mathrm{mg} / \mathrm{kg}$ de glicerina. 
DALMASO, A.C. et al. Glicerina bruta de biodiesel na alimentação de ruminantes. PUBVET, Londrina, V. 8, N. 12, Ed. 261, Art. 1733, Junho, 2014.

Todavia, os níveis máximos seguros de metanol na glicerina ainda precisam ser definidos.

Há substanciais evidencias que o uso da glicerina como macroingredientes na dieta reduz a espermatogênese. Recomenda-se o desenvolvimento de mais estudos confirmatórios e/ou estratégias para a redução desse efeito.

A segurança do uso de glicerina oriunda da transesterificação de gordura animal, bem como de óleos vegetais contendo toxinas ou fatores antinutricionais ainda necessitam ser avaliados.

O uso da glicerina na dieta apresenta potencial de reduzir a emissão de metano ruminal por unidade de matéria orgânica digestível ingerida, mas que ainda necessita de confirmação por meio de estudos in vivo de longa duração.

O uso da glicerina na dieta apresenta potencial de ampliar o fluxo intestinal de ácidos graxos insaturados dietéticos e aumentar a deposição dos mesmos na carcaça e a secreção no leite. No entanto, fazem-se necessários estudos confirmatórios in vivo.

\subsection{Conclusão}

O uso da glicerina na alimentação animal é uma saída, pois a mesma possui características interessantes como a alta energia disponível e o sabor adocicado, para o aumento da produção da mesma através do biodiesel, porém necessita-se de mais estudos quanto à toxidade do metanol e teor de inclusão na dieta.

\subsection{Referências bibliográficas}

ANP - AGÊNCIA NACIONAL DE PETRÓLEO, GÁS NATURAL E BIOCOMBUSTÍVEL. Biodiesel. Brasilia, $2010 . \quad$ Disponível em: $<$ www.anp.gov.br/?pg =17680\&m $=\& t 1=\& t 2=\& t 3=\& t 4=\& a r=\& p s=\&$ cachebust $=126675703150$ 0>. Acesso em: 05 abril 2013.

BIODIESELBR - Frente Parlamentar do Biodiesel. Disponível em: http://www.frentebio.com/2011/11/palestras-na-conferencia-do-biodieselbr.html>. Acesso em: 05 abril 2013. 
BOWKER, M. et al., Photocatalytic Reforming of Glycerol over Gold and Palladium as an Alternative Fuel Source. Journal Catalysis Letters. 128, p. 253-255, 2008

CERRATE, S. et al. Evaluation of glycerine from biodiesel production as a feed ingredient for broilers. International Journal of Poultry Science, Faisalabad, v. 5, n.11, p. 1001-1007, 2006.

CIMA - Chartered Institute of Mangement Accounts. Disponível em: <http://www.cimaglobal.com/Events-and-cpd-courses/globalbusinesschallenge> Acesso em: 03 abril 2013.

CHUNG, Y. H. et al. Effects of feeding dry glycerin to early postpartum Holstein dairy cows on lactational performance and metabolic profiles. J. Dairy Sci. v. 90, p. 5682-5691, 2007

CZERKAWSKI, J.W.; BRECKENRIDGE, G. Fermentation of various glycolytic intermediates and other compounds by rumen micro-organisms, with particular reference to methane production. British Journal of Nutrition. v. 27, p. 131-146, 1972.

DEFRAIN J.M.; HIPPEN, A.R.; KALSCHEUR, K.F. et al. Feeding glycerol to transition dairy cows: effects on blood metabolites and lactation performance. Journal of Dairy Science, v.87, p.4195-206, 2004.

DINIZ, G. De coadjuvante a protagonista: glicerina bruta obtida na produção de biodiesel pode ter muitas aplicações. Ciência Hoje On-line, Rio de Janeiro. Disponível em <http://cienciahoje.uol.com.br/controlPanel/materia/view/3973>. Acesso em: 04 abril 2013.

DONKIN, S.S. Glicerol from biodiesel production : the new corn for dairy cattle. Revista Brasileira de Zootecnia, v.37, suplemento especial, p.280-286, 2008.

DRACKLEY, J. K., M. J.; RICHARD, D. C.; Beitz, and J. W. Young. Metabolic Changes in Dairy Cows with Ketonemia in Response to Feed Restriction and Dietary 1,3-Butanediol. J. Dairy Sci. v. 75, p. 1622-1634, 1992.

ELAM, N.A.; ENG, K.S.; BECHTEL, B. et al. Glycerol from Biodiesel Production: Considerations for feedlot diets. Disponível em: $<$ http://ag.arizona.edu/ans/swnmc/Proceedings/2008/05Elam 08.pdf >. Acesso em: 04 abri 2013.

FÁVARO V. R., Utilização de glicerina, subproduto do biodiesel, na alimentação de bovinos. 2010. 48f. Dissertação (Mestre em Zootecnia) - Faculdade de Ciências Agrárias e Veterinárias, Universidade estadual Paulista "Julio de Mesquita Filho" Jaboticabal, 2010.

FNC - Federacion Nacional de Biocombustibles de Colombia. 2011. Estadísticas. Disponível em: http://www.fedebiocombustibles.com/v2.. Acesso em: 04 abril 2013.

GBC - Global Biofuels Center. 2011. TOP 25 - Global Ethanol and Biodiesel Production Capacity. Disponível em: http://www.globalbiofuelscenter.com/NM Top5.aspx.> Acesso em: 03 abril 2013

GOMES, M.A.B. Parâmetros produtivos e reprodutivos de ovinos suplementados com glicerina da produção de biodiesel. 2009. 60f. Dissertação (Mestrado em Zootecnia) - Universidade Estadual de Maringá, Maringá, 2009. 
IGDOURA, S.A.; WIEBE, J.P. Suppression of spermatogenesis by low-level glycerol treatment. Journal of Andrology, v.15, n.13, p.234-243, 1994.

JOHNSON, R. B. The treatment of ketosis with glycerol and propylene glycol. Cornell Veterinary, v.44, p.6-21, 1954.

KREHBIEL, C.R. Ruminal and physiological metabolism of glycerin. Journal of Animal Science, v.86, E-Suppl.2, p.392, 2008.

KRUEGER, N.A.; ANDERSON, R.C.; TEDESCHI, L.O. et al. Bioresource Tecnology. v. 101, p.8469-8472, 2010

LAGE, J.F. Glicerina bruta oriunda da agroindústria do biodiesel na alimentação de cordeiros em terminação. 2009. 72f. Dissertação (Mestrado em Zootecnia) - Universidade Federal de Viçosa, Viçosa, 2009.

Lehninger, A. L. et al. Princípios de bioquímica. 3 ed., São Paulo, 2000, p.39

LIN, E.C.C. Glycerol utilization and its regulation in mammals. Annual Review of Biochemistry, Palo Alto, v. 46, p. 765-795, 1977.

LINKE, P. E. J. M. et al. 2004. Ruminal and plasma responses in dairy cows to drenching or feeding glycerol. J. Dairy Sci. 87 Suppl. 1:343. (Abstr.)

LOFRANO, R.C.Z. Uma revisão sobre biodiesel. Revista científica do UNIFAE, v.2, 2008.

$\mathrm{MACH}, \mathrm{N}$. et al. Effects of crude glycerin supplementation on performance and meat quality of Holstein bulls fed high-concentrate diets. Journal of Animal Science, v.87, p.632-638, 2009.

MARCHETTI, J.M. et al. Possible methods for biodiesel production. Renewable and Sustainable Energy Reviews. 11, 1300-1311. 2007.

MENTEN, J.F.M. et al. Glicerol na alimentação animal. 2009. Disponível em: <http://www.agrolink.com.br/downloads/glicerol 2009-03-13.pdf> Acesso em: 03 abril 2013.

MOTA, C. J. A. et al. Gliceroquímica: novos produtos e processos a partir da glicerina de produção de biodiesel, Instituto de Química, Universidade Federal do Rio de Janeiro. Quimica Nova, Vol. 32, No. 3, p. 639-648, 2009.

OLIVEIRA, A.S. et al. Co-produtos do biodiesel na alimentação de ruminantes. In: V Simpósio sobre Manejo Estratégico da Pastagem, III Simpósio Internacional sobre Produção Animal em Pastejo ed.Viçosa. Anais... UFV, 2010, v.1, p. 419-462.

PEARSONS, G.L. et al. Performance and carcass traits of finishing heifers fed crude glycerin. Journal of Animal Science, v.87, p.653-657, 2009.

PERES, J.R.R. et al. BIOCOMBUSTIVEIS. Uma oportunidade para o agronegócio brasileiro. Revista de Política Agrícola, Brasília, v. 1, p. 31-41, 2005.

PINTO, A. C. et al. Biodiesel: An overview. Journal of the brazilian chemical society, v. 16, p. $1313-1330,2005$.

POUSA, G.P.A.G. et al. History and policy of biodiesel in Brazil. Energy Policy. 35, 5393-5398, 2007 
REMOND, B. et al. In vitro and in vivo fermentation of glycerol by rumen microbes. Animal Feed Science and Technology, v.41, p.121-132, 1993.

RIVALDI, J. D. et al. Glicerol de biodiesel. Biotecnologia Ciência de Desenvolvimento. N.37, p.45-51, 2007.

SAN VITO, E.S. et al. Glicerina bruta do biodiesel na alimentação de vacas leiteiras. In: REUNIÃO ANUAL DA SOCIEDADE BRASILEIRA DE ZOOTECNIA, 47. 2010, Salvador. Anais...Salvador: Sociedade Brasileira de Zootecnia, 2010. p.1-3 [ CD-Rom].

SCHRÖDER, A.; SÜDEKUM, K. H.; Glycerol as a by-product of biodiesel production in diets for ruminants Australia. In: Wratten N, Salisbury PA editor. Paper no. 241 in New Horizons for an Old Crop. Proc. 10th Int. Rapeseed Congr. Canberra. Gosford, New South Wales, Australia: The Regional Institute Ltd; 1999;

SEIDEL, B. et al. Safety Evaluation for a Biodiesel Process Using Prion-Contaminated Animal Fat as a Source. Environment Science \& Pollution Research, v.13m n.2, p.125-130, 2006.

SOUZA, G.S. et al. Análise da potencialidade da produção de biodiesel a partir de óleos vegetais e gorduras residuais. In: Seminário de iniciação científica da UESC, Santa Cruz. Anais... Santa Cruz: UESC, 2007. P.477-478.

THOMPSON, J.C.; HE, B.B. Characterization of crude glycerol from biodiesel production from multiple feedstocks. Applied Engineering in Agriculture, v.22, p.261-265, 2006

VALADARES FILHO, S.C. et al. Tabelas brasileiras de composição de alimentos para bovinos. 2.ed. Viçosa : UFV, DZO, 2006. 329p.

WIEBE, J.P. et al. Glycerol disrupts tight junction-associated actin microfilaments, occluding, and microtubules in sertoli cells. Journal of Andrology, v.21, n.5, p.625-635, 2000.

ZACARONI O. F., Resposta de vacas leiteiras à substituição de milho por glicerina bruta. 2010. 43f. Dissertação (Mestre em Veterinária) - Programa de Pós-Graduação em Ciências Veterinárias, Universidade Federal de Lavras, Lavras, 2010. 